Journal of Engineering and Applied Sciences 14 (8): 2497-2503, 2019

ISSN: 1816-949X

(C) Medwell Journals, 2019

\title{
Review of Possibilities to Use Alternative Fuels as Energy Source for Cement Production
}

\author{
Nurten Deva and Bersant Beka \\ Department of Materials and Metallurgy, University of Mitrovica, Mitrovica, Kosova
}

\begin{abstract}
Usage of alternative fuels as energy sources of cement industry is practice which is proven as very effective way of waste utilization in cement factories over the world, more and more. The years of experience in the utilization of alternative fuels, mainly waste in the cement industry around the world show that their application is justified from all points of view. Many wastes created during the several processes in the industry or from external sources have pretty good potential for use for cement manufacture, either as fuels or replacement of raw materials, hence, this industry is actively pursuing their beneficial use within its processes. Energy costs and environmental standards encouraged cement manufacturers world-wide to evaluate to what extent conventional fuels can be replaced by alternative fuels with processed waste materials. In this study, primary types of alternative fuels that can be used instead of the non-renewable fuels for cement production in Sharrcem company are presented and reviewed. The significant role of cement production in overall sustainable development is manifested in the use of alternative materials in order to achieve the highest possible ecological balance while maintaining optimum acceptability criteria for the cement and construction industry.
\end{abstract}

Key words: Energy sources, non-renewable, utilization, waste, application, industry

\section{INTRODUCTION}

In the modern world, the demand for non-renewable energy sources is increasing day by day due to modernization of mechanization. Fossil fuels are still being created by underground heat and pressure; they are being consumed more rapidly than they are being created. Insufficient quantities or unreasonable price of petroleum fuels deeply concerns us whereas the renewable energy is a promising alternative solution because it is clean and environmentally safe (Ayhan, 2007). For the leading industries (metallurgy, cement, etc.) the use of refuse derived fuel in the rotary kilns, decreases significantly the costs for fossil sources of heat energy. Within the years these sectors are facing growing challenges towards saving materials and energy carriers as well as minimizing the $\mathrm{CO}_{2}$ emissions in order to ensure a sustainable future both for the societies and for the branch (Theulen and Kilns, 2018).

The possibility to use the different types of waste with high caloric value as Alternative Fuels (AF) in the cement industry has been developed and widely spread during the last few decades. Such materials could be successfully and safety used without increased effects on the environment, due to favourable combustion conditions in the cement production process. Use of $\mathrm{AF}$ is necessary to be aligned with regulations and process required criteria for its development. Strict control over AF composition and caloric value, process parameters, products and emissions in the environment should be assured. To achieve greater sustainability of its manufacturing process it is essential that all available energy resources are used efficiently and effectively. This study except the possibility to use the $\mathrm{AF}$ in cement industry include and reviews literature on the usage of different types of industrial fuels, their advantages, disadvantages, selection criteria and impacts on environment (Deva, 2013).

Many wastes created during the several processes in the production industry or from external sources have potential for use for cement manufacture, either as fuels or replacement of raw materials, hence, this industry is actively pursuing their beneficial use within its processes. The Kosovo Government has committed itself to the EU Landfill Directive and other international agreements that aim to reduce disposal of wastes to landfill and to recovering energy and materials from used tires, packaging wastes, solvents and many other waste streams. Therefore, the Kosovo's cement industry is playing a vital role in helping to achieve the environmental objectives by utilizing of appropriate wastes as $\mathrm{AF}$ and raw materials in the cement manufacture.

Corresponding Author: Nurten Deva, Department of Materials and Metallurgy, University of Mitrovica, Mitrovica, Kosova 
(a)

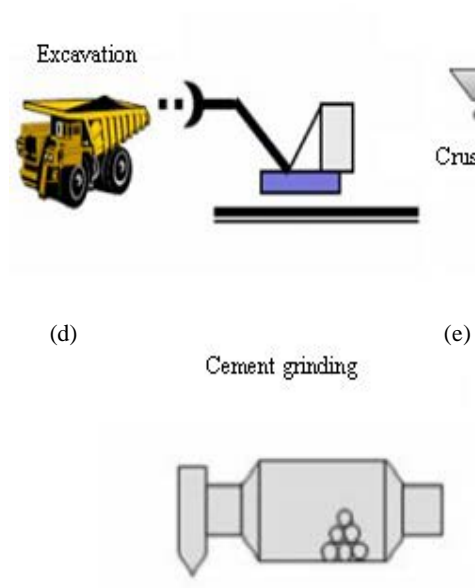

(e) (b)

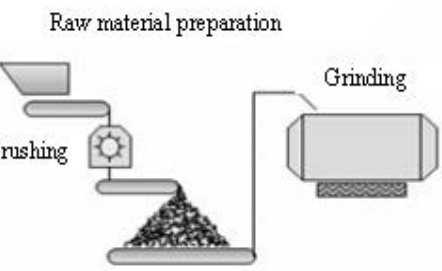

(c)

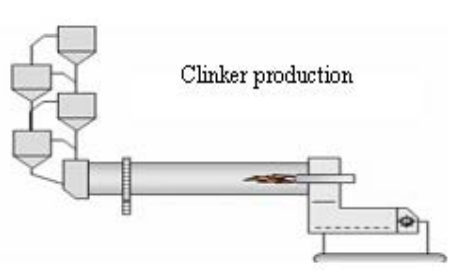

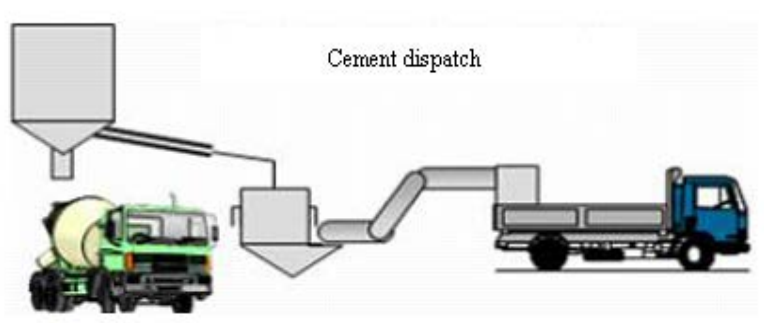

Fig. 1: a-e)Cement manufacturing processes

\section{DATA ABOUT THE SHARRCEM COMPANY}

Sharrcem was established in 1936, marking the first manufacturer company of cement in Kosovo. Standard designed cement capacity volume of Sharrcem is 1500 ton/day or 1,200,000 t/an. Today, company enjoys an important reputation by the standards it has managed to incorporate in the production process and is one of the leading company which respects the health and safety of its workforce and make significant investments in tackling issues that are critical to the protection and promotion of a healthy environment for the community. Company is committed to implement the conditions of work, in all aspects, by all parties and as a result of this commitment, this company is certified by ISO Standards for Quality (ISO 9001), environment (ISO 14001) and Operational Health and Safety (OHSAS ISO 18001). As a result of ISO Certifications Company has been awarded the first ever IPPC (Integrated Prevention Pollution and Control) permit issued in the country. Company throw a further step, through fulfilling the standard practices of today for the international cement industry by provision of the usage of $\mathrm{AF}$ and alternative raw materials in the cement manufacturing process. As both these alternative resources positively contribute in energy recovery and reduction of waste, they are highly recommended by the international sustainability standards Sharrcem facts.

Description of technological process for cement production: The process of cement production is a complex process which consists of several phases and activities that are part of joined process in which are included that are shown in Fig. 1:

- Exploitation of raw material (marl stone)

- To prepare raw materials and their storage
- Grinding and raw meal storage

- Clinker production

- Cement production grinding

- Packing and dispatch

The production starts with the excavation of the raw materials. The main raw materials for cement production are limestone (calcium carbonate) and other materials as clay. Ideally as in the case of Sharrcem if the raw material is marl which has appropriate contend of limestone and clay and often is called "Natural cement". Chemical composition of raw materials components are shown in Table 1. The second phase is the preparation of the raw material which consists of initial crushing and grinding of the raw materials. The third phase is the production clinker which is the basic semi-final product of the cement. This part of the process is the most important in terms of emissions potential and of product quality and cost. In clinker burning, the raw meal is fed to the rotary kiln system where it is dried, preheated and sintered to produce cement clinker. In the clinker burning process, high process temperatures are required to convert the raw material mix into cement clinker. It is essential to maintain kiln charge temperatures in the sintering zone of the rotary kilns at between $1400-1500^{\circ} \mathrm{C}$ and the flame temperature at about $2000^{\circ} \mathrm{C}$. Also, the clinker needs to be burned under oxidizing conditions. Therefore, an excess of air is required in the sintering zone of a cement clinker kiln. The clinker is cooled with air and then stored. The final phase is the grinding of the cement. In this phase, clinker is grinded together with gypsum and other additional material as puzzolana, fly ash, limestone, furnace slag, etc., in a finely determined proportion in order to get product which has to comply with a very strict quality standards defined with the European Norms under EN 197-1. 
J. Eng. Applied Sci., 14 (8): 2497-2503, 2019

Table 1: Chemical composition of raw material for cement production

\begin{tabular}{|c|c|c|c|c|c|c|c|c|}
\hline Composition & Marl (\%) & Lime stone $(\%)$ & Opalit (\%) & Gypsum (\%) & Raw meal comp. (\%) & Fly ash-KEK (\%) & Pyrite $(\%)$ & KEK ash (\%) \\
\hline $\mathrm{SiO}_{2}$ & 13.52 & 1.45 & 72.88 & & 13.14 & 29.17 & 5.50 & 44.2 \\
\hline $\mathrm{Al}_{2} \mathrm{O}_{3}$ & 3.51 & 0.33 & 9.04 & & 3.46 & 9.42 & 0.62 & 9.75 \\
\hline $\mathrm{Fe}_{2} \mathrm{O}_{3}$ & 1.71 & 0.3 & 1.94 & & 2.54 & 7.0 & 71.06 & 5.27 \\
\hline $\mathrm{CaO}$ & 41.39 & 53.72 & 0.75 & & 42.11 & 33.19 & 2.88 & 11.97 \\
\hline $\mathrm{MgO}$ & 1.60 & 0.93 & 0.09 & & 2.08 & 3.95 & 1.64 & 2.76 \\
\hline $\mathrm{SO}_{3}$ & 0.06 & 0.01 & 0.35 & 43.52 & 0.34 & 10.74 & 6.51 & 1.29 \\
\hline $\mathrm{K}_{2} \mathrm{O}$ & 0.53 & 0.04 & 0.24 & & 0.46 & 0.55 & 0.12 & 0.74 \\
\hline $\mathrm{Na}_{2} \mathrm{O}$ & 0.09 & 0.03 & 0.08 & & 0.13 & 1.12 & 0.01 & 1.0 \\
\hline Moisture & 14.0 & 0.5 & 17.25 & 19.24 & & & & 28 \\
\hline Los on ignite & 37.17 & 41.58 & 5.55 & & 36.24 & 2.92 & & 21.017 \\
\hline
\end{tabular}

The production of cement consumes large quantities of raw materials and energy such are thermal and electricity. This process requires approximately 3.2-6.3 GJ of energy and 1.7 tons of raw materials (mainly limestone) per ton of clinker produced (Oss and Padovani, 2002). Being an energy intensive industry in cement industry thermal energy is accountable for about $20-25 \%$ of the cement production cost (Madlool et al., 2011), during the process thermal energy is used mainly during the calcinations process. All products that are produced in the Sharr cem are certified by European Quality Norms EN 197-1:

- $\quad \mathrm{CEM} \amalg / \mathrm{B}-\mathrm{M}(\mathrm{P}, \mathrm{W})-42.5 \mathrm{R}$, widely used cement with high strength

- $\quad$ CEM $\Pi / \mathrm{B}-\mathrm{M}(\mathrm{P}, \mathrm{W})-42.5 \mathrm{~N}$

- $\mathrm{CEM}$ IV/B (P, W)-32.5 R best choice for cost effective construction

- CEM I - 52.5N, superior cement for very responsible constructions

- MC 5 (Sharrmall) masonry mortar

\section{OVERVIEW OF ALTERNATIVE FUELS USED BY CEMENT INDUSTRY}

Cement is considered one of the most important building materials around the world and therefore, this chapter reviews in detail some of the main $\mathrm{AF}$ used in cement production. It focuses on types of $\mathrm{AF}$ used, the environmental and socio-economic benefits of using $\mathrm{AF}$, challenges associated with switching from conventional to $\mathrm{AF}$, combustion characteristics of the $\mathrm{AF}$ concerned and their effect on cement production and quality. The AF offers a valuable source of energy for cement producers that are interested in its use. $\mathrm{AF}$ here refers to fuels that can be used instead of conventional fuels such as coal, oil and natural gas. Most cement kilns today use coal and petroleum coke as primary fuels. Traditionally, fossil fuels have been burnt to generate the temperatures of around $1450-1500^{\circ} \mathrm{C}$ needed to produce cement. Selected waste and by-products with recoverable calorific value can be used as fuels in a cement kiln, replacing a portion of conventional fossil fuels, if they meet strict specifications. Fuels in various countries have been prepared from mixed types of waste in order to ensure the better use of the chemical energy contained in waste. It is now established that processed waste with energy content can be utilized as an energy source. To be able to use any of these fuels in a cement factory, it is necessary to know the composition of the fuel. The choice is normally based on price and availability. The energy and ash contents are also important as are the moisture and volatiles contents (Mokrzycki and Uliasz-Bochenczyk, 2003). All kinds of varieties from liquid to solids, powdered or as big lumps can be encountered when dealing with $\mathrm{AF}$, requiring a flexible fuel feeding system. Somehow, they should all be fed into the burning chamber of the process. It may be fed directly into the burning zone in the kiln itself or into the preheating system for dissociating part of the carbonates from the meal before it enters the kiln for clinker formation (Kaantee et al., 2004).

Substitution of non-renewable fuels with alternative fuels: Manufacturing processes of cement are based on the phases that are developed in high temperatures where large amounts of energy are needed to create appropriate condition for physical and chemical transformation of raw material into final products. The adequate choice of the fuel and other energy sources for a process depend on many technical-technological factors such as: quality of fuel's heat combustion, combustion intensity, chemical composition, temperature of combustion, etc. and depending on the following economic factors: resource reserves, supplying possibilities, price of energy source, etc. Considering the actual ever increasing prices of fuels and environmental issues, attempts are being made from production entities and scientific-research institutions to analyze the possibility of replacing non-renewable energy sources with other types of fuel such are $\mathrm{AF}$.

There are several key performance indicators to measure the performance of cement manufacturing plant and most of them are related to the thermal efficiency of the plant. This study summarizes the current practices of using $\mathrm{AF}$ in cement industry and attempts to draw a relationship between the usage percentage of $\mathrm{AFs}$ and the plant performance. A variety of research journals, 
conference proceedings, books, industrial sustainability reports and reliable websites are included in this review. A brief discussion has been appended to understand the correlation between the blended AFs and plant performance which might be useful for cement producers and the researchers. $\mathrm{AF}$ are used in many cement plants throughout the world. Several cement plants in Poland are using AF. Among these plants, are Lafarge Concerns that has begun using $\mathrm{AF}$ in the early 1990s, CMA, 2003 (Anonymous, 2003, 2009, 2011). Lafarge plants uses AF made from waste. The incineration of AF in cement plants is a safe method for the utilization of waste that is ecologically friendly and profitable for the industrial plants and society (Jenkins and Mather, 1997). The cement industry is an energy intensive industry. The average energy demand for the production of 1 ton of cement is about 3.3. GJ (Liu et al., 1995) which corresponds to $120 \mathrm{~kg}$ of coal with a calorific value of $27.5 \mathrm{MJ} / \mathrm{kg}$.

Generally fossil fuels such as coal, petroleum coke (petcoke) and natural gas provide the thermal energy required for cement industry. Usage of Alternative Fuel (AF) becomes more popular to the cement manufacturer due to increasing fossil fuel prices, limited fossil fuel resources and environmental concerns. $\mathrm{AF}$ cover all non-fossil fuels and waste from other industries including tyrederived fuels, biomass residues, sewage sludge and different commercial and industrial wastes (Nielson et al., 2011).

Coal and pet Coke, two of the most carbon-intensive fuels are typically used to heat cement kilns. Most of AF have a lower carbon intensity than coal or pet Coke. According to the International Energy Association, these mixed fuels can be $20-25 \%$ less carbon-intensive than traditional fossil fuels (Madlool et al., 2011). Using alternatives to coal and pet coke as replacement fuels in a cement kiln can significantly reduce greenhouse gas emissions and in some cases other air pollutants.

The cement manufacturing industry is under increasing pressure from the environmental protection agencies to reduce the emissions of green house gases. The usage of $\mathrm{AFs}$ in cement manufacturing not only helps to reduce the emission but also has significant ecological benefits of conserving non-renewable resources (Trezza and Scian, 2000). The substitution rate of fossil fuel by AFs varies from country to country. Most of the European countries are way ahead in the usage percentage of AFs than the rest of the world. World's leading cement producers are currently using AFs in a large extent and pursuing to increase it even more by 2020. Conventional fossil fuel substitution rate and the percentage of different AFs usage by different cement production group are available in their sustainable development reports.
Criteria of alternative fuel use: There are no set criteria for selecting AFs today. The specific criteria that a material must meet in order to be considered as a fuel is typically set by the individual cement producer according to their own needs. AFs are generally a mixture of various wastes and therefore, consistency in their composition cannot be guaranteed. There is a need for ensuring the chemical contents of the $\mathrm{AF}$ that meets regulatory requirements for environmental protection. The following properties are expected to be considered as AF (Madlool et al., 2011; Mokrzycki and Uliasz-Bochenczyk, 2003):

- Physical state of the fuel (solid, liquid, gaseous)

- Content of circulating elements $(\mathrm{Na}, \mathrm{K}, \mathrm{Cl}, \mathrm{S})$

- Toxicity (organic compounds, heavy metals)

- Composition and content of ash and content of volatiles

- Calorific value over $14.0 \mathrm{MJ} / \mathrm{kg}$

- Chlorine content $<0.2 \%$ and Sulfur content $<2.5 \%$

- $\quad$ PCB content $<50 \mathrm{ppm}$

- Heavy-metals content $<2500$ ppm [out of which: Mercury (Hg) $10 \mathrm{ppm}$ and total Cadmium (Cd) Thallium (Tl) and mercury ( $\mathrm{Hg})<100 \mathrm{ppm}$ ]

- Grinding properties

- Moisture content

- Proportioning technology

- The emissions released

- The cement quality and its compatibility with the environment must not decrease

- AF must be economically viable

Advantages and disadvantages of alternative fuels: Alternative fuels generally talking are cheaper than the fossil fuels; most of them are generated from wastes which only require some processing cost. A mixture of fossil fuels and $\mathrm{AF}$ in optimal proportion is used to produce the thermal energy required in cement industry. The significant advantage of alternative fuel substitution is the preservation of non renewable energy sources (Willitsch et al., 2002) and the reduction of waste disposal sites. Switching to alternatives fuels presents several challenges as they have different characteristics compared to the conventional fuels. Poor heat distribution, unstable pre-calcine operation, blockages in the pre-heater cyclones, build-ups in the kiln riser ducts, higher $\mathrm{SO}_{2}$, NOX and $\mathrm{CO}$ emissions and dusty kilns are some of the major challenges which need to be addressed (Trezza and Scian, 2000). One potential constraint on the implementation of $\mathrm{AF}$ is the final clinker composition, since, the combustion by-products are incorporated into clinker (Chinyama, 2011). The substitution of AFs inherently requires initial investment costs associated with adjustment or replacement of burner, establishment of alternative 
fuel delivery systems, new fuel storage facilities and fuel distribution systems (Akkapeddi, 2008).

Impacts of alternative fuels in cement quality: The main indicators of cement quality are the requirements for mechanical, physical and chemical properties which are standardised in harmonised European/national product specifications British Standards Institution. These requirements must be met regardless of either the type of fuel used or the nature of the raw materials. These properties are measured and monitored continually, under independent third party scrutiny in order to ensure that cement conforms to its specification and can be legally placed on the market. The use of wastes has no effect on these major properties because any potential effects will have been accounted for by making compensatory adjustments to the chemical composition of the raw material fed to the kiln.

Usage of alternative fuels in Sharrcem: Cement factories worldwide, consume about $190 \mathrm{mln}$. ton of coal for clinker production. This consumption can spoil ecological balance on Earth. For this reason in last year's, developed countries are searching for solutions that would preserve energetic recourses and setting "friendly" technologies, in order to protect living environment. The best solution is the use of different types of wastes as an alternative energy source, shown in Fig. 2. Their utilizing on the other hand will improve environmental protection that is achieved by reducing of pollutants emissions and in same time environmental is cleaned from the waste. Handling and using them means:

- Reduction of areas used for their deposite

- Reduce of the risks of pollution of underground waters and soil

- Reduction of possibilities of air pollution

- Reduction of $\mathrm{CO}_{2}$ emissions

Various $\mathrm{AF}$ can be used to provide the heat and the energy required for the cement production process. Different types of $\mathrm{AF}$, obtained from waste materials can replace primary raw materials and/or fossil fuels in cement manufacturing and will contribute to save natural resources. Based on abovementioned facts, the sharrcem company has undertake a further steps, through the fulfilling of criteria of the standard practices of international cement industry by provisional usage of $\mathrm{AF}$ and Alternative Raw Materials (ARM) in the cement manufacturing process. Both these alternative resources have positively contributed in energy recovery and in waste reduction, hence, they are highly recommended for

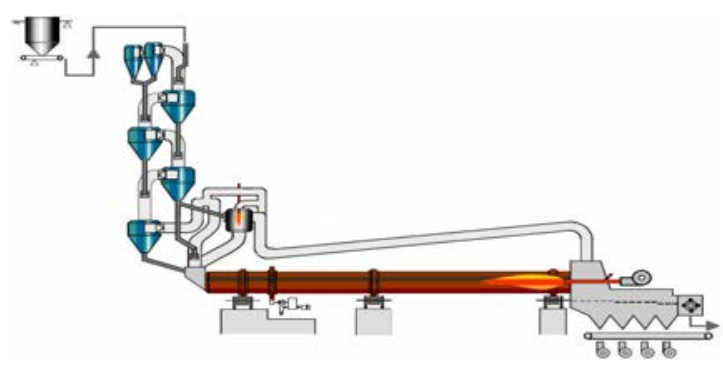

Fig. 2: Alternative fuels utilizing processes

the utilizing based on the international sustainability standards. Sharrcem will first of all will push forward Kosovo obligations regarding reduction of greenhouse gasses utilizing $\mathrm{AF}$ and raw materials. The Kosovo Government has committed itself to the EU Landfill Directive and other international agreements that aim to reduce disposal of wastes to landfill and to recovering energy and materials from used tyres, packaging wastes, solvents and many other waste streams. Therefore, the Kosovo's cement industry is playing a vital role in helping to achieve the environmental objectives by utilising of appropriate wastes as $\mathrm{AF}$ and raw materials in the cement manufacture.

Basically, characteristics of the clinker burning process itself allow environmental beneficial waste-to-energy and material recycling applications. This enables the cement industry to contribute further to the reduction of greenhouse gas emissions and to the use of fewer natural resources.

Possible alternative fuels utilized in cement production: From what is said above, comes the conclusion that positive experience on utilizing of wastes as alternative fuel or/and raw material is day after day bigger in various production processes. More information about waste used as $\mathrm{AF}$ in cement industry are given in bellow chapter. One of energy types gained from material remnants that is applied in cement factories in Europe is energy gained from treating of public recycling wastes as $\mathrm{AF}$ known as $\mathrm{RDF}$. Company have made feasibility study for production of RDF fuel from public solid wastes that are recyclable wastes from waste collecting points. Utilizing RDF as alternative energy in Sharrcem plant and co-procesing in rotary kiln will be achieved positive effects on environment such as:

- Reduction of wastes in landfills/collecting points

- Complete utilization of energy

- Avoiding of ash as waste and relate it to clinker

- Save of conventional energy 
Essential process characteristics for the use of $\mathrm{AF}$ According to EU, to achieve safe decomposition is to coprocess them at following conditions:

- Maximum temperatures of approx. $2000^{\circ} \mathrm{C}$ (main firing system, flame temperature) in rotary kilns

- Gas retention times of about $8 \mathrm{sec}$ at temperatures above $1200^{\circ} \mathrm{C}$ in rotary kilns

- Material temperatures of about $1450^{\circ} \mathrm{C}$ in the sintering zone of the rotary kiln

- Oxidising gas atmosphere in the rotary kiln

- Gas retention time in the secondary firing system of more than $2 \mathrm{sec}$ at temperatures of above $850^{\circ} \mathrm{C}$; in the precalciner

- The retention times are correspondingly longer and temperatures are higher

- Solids temperatures of $850^{\circ} \mathrm{C}$ in the secondary firing system and/or the calciner

- Uniform burn-out conditions for load fluctuations due to the high temperatures at sufficiently long retention times

- Destruction of organic pollutants due to the high temperatures at sufficiently longretention times

- Absorption of gaseous components like $\mathrm{HF}, \mathrm{HCl}$, $\mathrm{SO}_{2}$, on alkaline reactants

- Complete utilization of fuel ashes (including most heavy metals). They are incorporated in the complex matrix of clinker

Types of waste used as alternative fuels in cement industry: The clinker burning process offers prety good conditions to use the different types of waste materials as $\mathrm{AF}$ which can subsitute partially conventional fuel used. However, kilns must to fullfil some required criteria of $\mathrm{AF}$ use and to have ability for their burning and as well and other circumstances have to be optimized in order to e able to achieve the high energy efficiency. Table 2 shows examples of calorific values of different waste materials that can be possible to be used as $\mathrm{AF}$ in cement plant. Sharrcem company comply with general policies of Titan Group and fulfilling of legal obligations in accordance with local and European Union regulations for a sustainable environment. Replacement of existing technologies in Sharrcem Company is done in accordance with Best Available Techniques (BAT) for cement industries which include the use of different types of $\mathrm{AF}$, coming from waste materials which can replace primary raw materials and/or fossil fuels in cement manufacturing and will contribute to saving natural resources. Basically, characteristics of the clinker burning process itself allow environmental beneficial waste-to-energy and material
Table 2: Different types of waste materials that can be used as AF

\begin{tabular}{lc}
$\begin{array}{l}\text { Examples of types of AF fuels } \\
\text { (hazardous and non-hazardous) }\end{array}$ & $\begin{array}{c}\text { Examples of calorific values } \\
\text { GJ/t (MJ/kg) }\end{array}$ \\
\hline Wood & Approx. 16 \\
Paper, cardboard & $3-16$ \\
Textiles & up to 40 \\
Plastics & $17-40$ \\
Processed fractions (RDF) & $14-25$ \\
Rubber/tyres & Approx. 26 \\
Whole tires & Approx. 30 \\
Industrial sludge & $8-14$ \\
Municipal sewage sludge & $12-16$ \\
Animal meal & $14-18$ \\
Fats & $27-32$ \\
Coal/carbon waste & $20-30$ \\
Agricultural waste & $12-16$ \\
Solid waste (impregnated sawdust) & $14-28$ \\
Solvents and related waste & $20-36$ \\
Oil and oily waste & $25-36$ \\
Oil-shale based fuel mix (85-90\% oil-shale) & 9.5 \\
Sewage sludge (moisture content $>10 \%)$ & $3-8$ \\
Sewage sludge (moisture content $<10-0 \%)$ & $8-13$ \\
\hline
\end{tabular}

recycling applications and enables the cement industry to contribute further to the reduction of greenhouse gas emissions.

\section{CONCLUSION}

The analysis presented in the current study shows that the using of $\mathrm{AF}$ in particular, for cement production is an actual topic and complex solution with huge technological, energetical, ecological and economical advantages. This leads to a sustainable and mutually beneficial solution, in compliance with the package of measures for the circular economy, adopted by the European Commission at the end of 2015. Many years of experience in several industries have shown that the use of wastes as $\mathrm{AF}$ in cement plants around the world, justified their application. The substitution of conventional fossil fuels with $\mathrm{AF}$ will reduce energy costs, providing a competitive edge for a cement plant using this source of energy. According to all mentioned facts in this study, it can be concluded that concept of use of $\mathrm{AF}$ in cement industry is multiple useful from more different aspects. The obtained results could be used also in other industrial branches with high energy consumption, like metallurgy. Besides, every company which manipulates with big amount of waste would prefer to deliver waste to the cement factories instead to the depots. Furthermore, this will reduce the burden of waste disposal considerably. Finally, this concept achieves saving of nonrenewable fuels, i.e., fossil fuels which were primary fuels in world cement. The significant role of cement production in overall sustainable development is manifested in the use of alternative materials in order to 
achieve the highest possible ecological balance while maintaining optimum acceptability criteria for the cement and construction industry. In present study is discussed about the utilizing of AF in Kosova. Based in facts discussed, it can be concluded that the Kosovo's Government should support initiatives from different branches of industry related this issue with the respective grants and to raise this issue in higher levels, considering that this issue is very essential for sustainable economic development of country.

\section{REFERENCES}

Akkapeddi, S., 2008. Alternative solid fuels for the production of Portland cement. Ph.D Thesis, Auburn University, Auburn, Alabama.

Anonymous, 2003. Cement statistics. Cement Manufaturers Association, Noida, India.

Anonymous, 2009. Cement technology roadmap 2009: Carbon emissions reductions up to 2050 . International Energy Agency, Paris, France. https://www.iea.org/publications/freepublications/ publication/Cement.pdf

Anonymous, 2011. Cement-Part 1: Composition, specifications and conformity criteria for common cements: European Standards Organisation BS EN 197-1. British Standards Institution, UK.

Ayhan, D., 2007. Biodiesel: A Realistic Fuel Alternative for Diesel Engines. Springer, Berlin, Germany, ISBN:978-1-84628994-1, Pages: 207.

Chinyama, M.M.P., 2011. Alternative Fuels in Cement Manufacturing. In: Alternative Fuel, Manzanera, M. (Ed.). InTech, Rijeka, Croatia, ISBN:978-953-307-372-9, pp: 264-284.
Deva, N., 2013. Substitution of mazout with coal powder during cement production and environmental effects. J. Intl. Environ. Appl. Sci., 8: 295-298.

Jenkins, B.G. and S.B. Mather, 1997. Fuelling the demand for alternatives. Cem. Environ. Yearbook, 1997: 90-97.

Kaantee, U., R. Zevenhoven, R. Backman and M. Hupa, 2004. Cement manufacturing using alternative fuels and the advantages of process modelling. Fuel Process. Technol., 85: 293-301.

Liu, F., M. Ross and S. Wang, 1995. Energy efficiency of China's cement industry. Energy, 20: 669-681.

Madlool, N.A., R. Saidur, M.S. Hossain and N.A. Rahim, 2011. A critical review on energy use and savings in the cement industries. Renewable Sustainable Energy Rev., 15: 2402-2460.

Mokrzycki, E. and A. Uliasz-Bochenczyk, 2003. Alternative fuels for the cement industry. Appl. Energy, 74: 95-100.

Nielsen, A.R., R.W. Aniol, M.B. Larsen, P. Glarborg and K. Dam-Johansen, 2011. Mixing large and small particles in a pilot scale rotary kiln. Powder Technol., 210: 273-280.

Oss, V.H.G. and A.C. Padovani, 2002. Cement manufacture and the environment: Part I: Chemistry and technology. J. Ind. Ecology, 6: 89-105.

Theulen, J. and C. Kilns, 2018. A ready made waste to energy solution. WEKA Industrie Medien $\mathrm{GmbH}$, Vienna, Austria. https://waste-management-world. $\mathrm{com} /$

Trezza, M.A. and A.N. Scian, 2000. Burning wastes as an industrial resource: Their effect on portland cement clinker. Cem. Concr. Res., 30: 137-144.

Willitsch, D.F., G. Sturm, F. Wurst and T. Prey, 2002. Alternative fuels in the Cement-industry. PMT-Zyklontechnik GmbH, Krems, Austria. 